EPJ Web of Conferences 87,02008 (2015)

DOI: $10.1051 /$ epjconf/ 20158702008

(C) Owned by the authors, published by EDP Sciences, 2015

\title{
42GHz ECRH assisted Plasma Breakdown in tokamak SST-1
}

B. K. Shukla, S. Pradhan, Paresh Patel, Rajan Babu, Jatin Patel, Harshida Patel, Pragnesh Dhorajia, V. Tanna, P K Atrey, R Manchanda, Manoj Gupta, Shankar Joisa, C N Gupta, Raju Danial, Prashant Singh, R. Jha, D. Bora and SST-1 Team

Institute for Plasma Research

Bhat, Gandhinagar-382428

Email: shukla@ipr.res.in

\begin{abstract}
In SST-1, 42GHz ECRH system has been commissioned to carry out breakdown and heating experiments at $0.75 \mathrm{~T}$ and $1.5 \mathrm{~T}$ operating toroidal magnetic fields. The 42GHz ECRH system consists of high power microwave source Gyrotron capable to deliver $500 \mathrm{~kW}$ microwave power for $500 \mathrm{~ms}$ duration, approximately 20 meter long transmission line and a mirror based launcher. The ECRH power in fundamental O-mode \& second harmonic X-mode is launched from low field side (radial port) of the tokamak. At $0.75 \mathrm{~T}$ operation, approximately $300 \mathrm{~kW}$ ECH power is launched in second harmonic $\mathrm{X}$-mode and successful ECRH assisted breakdown is achieved at low loop_voltage $\sim 3 \mathrm{~V}$. The ECRH power is launched around $45 \mathrm{~ms}$ prior to loop voltage. The hydrogen pressure in tokamak is maintained $\sim 1 \times 10^{-5} \mathrm{mbar}$ and the pre-ionized density is $\sim 4 \times 10^{12} / \mathrm{cc}$. At $1.5 \mathrm{~T}$ operating toroidal magnetic field, the $\mathrm{ECH}$ power is launched in fundamental Omode. The ECH power at fundamental harmonic is varied from $100 \mathrm{~kW}$ to $250 \mathrm{~kW}$ and successful breakdown is achieved in all ECRH shots. In fundamental harmonic there is no delay in breakdown while at second harmonic $\sim 40 \mathrm{~ms}$ delay is observed, which is normal in case of second harmonic ECRH assisted breakdown.
\end{abstract}

\section{Introduction}

The electron cyclotron resonance heating (ECRH) has shown several advantages from plasma start-up to MHD control in various tokamaks [1-9]. The $42 \mathrm{GHz} / 500 \mathrm{~kW}$ ECRH system is used in tokamak SST-1 [10] to carry out experiments related ECRH assisted breakdown and start-up at fundamental and second harmonic. The SST-1 [11,12] is a steady-state superconducting tokamak. The major radius of tokamak is $1.1 \mathrm{~m}$ and minor radius is $0.2 \mathrm{~m}$. The operating toroidal magnetic field of SST-1 is $0.75 \mathrm{~T}$ and $3.0 \mathrm{~T}$, however in the beginning phase of tokamak, it is operated at $0.75 \mathrm{~T}$ and $1.5 \mathrm{~T}$ magnetic fields. The SST-1 tokamak is equipped with all standard diagnostics to measure the plasma parameters like $\mathrm{H}_{\alpha}$, density, loop voltage, plasma current, soft X-rays, hard X-rays etc. The $42 \mathrm{GHz}$ ECRH system consists of Gyrotron, transmission line and a mirror based launcher. The Gyrotron is capable to deliver $500 \mathrm{~kW}$ power for $500 \mathrm{~ms}$ duration at $50 \mathrm{kV}$ beam voltage and $20 \mathrm{~A}$ beam current. Initially, the Gyrotron is tested on dummy load, after successful testing at full parameters on dummy load, the system is connected to tokamak using corrugated waveguide based transmission line system. The transmission 
line consists of a matching optic unit, DC break, $63.5 \mathrm{~mm}$ diameter corrugated waveguides, bend with bi-directional couplers, polarizer and bellow etc. The total transmission loss in the line is less than $1.1 \mathrm{~dB}$.

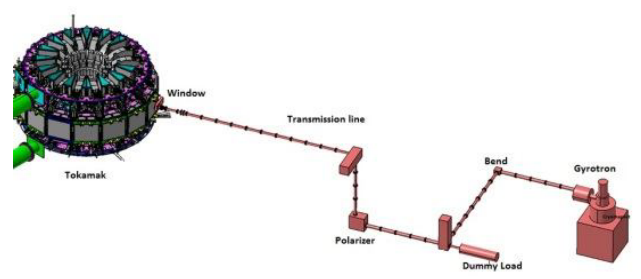

Figure 1 (42GHz ECRH system on tokamak SST-1)

The plasma breakdown and start-up experiments at fundamental and second harmonic are carried out in SST-1 using $42 \mathrm{GHz}$ ECRH system. At $0.75 \mathrm{~T}$ operation, approximately $300 \mathrm{~kW}$ ECH power is launched in second harmonic X-mode and successful ECRH assisted breakdown is achieved at low loop voltage $\sim 3 \mathrm{~V}$. The ECRH power is launched around $45 \mathrm{~ms}$ before the loop voltage. The hydrogen pressure in tokamak is maintained $\sim 1 \times 10^{-5} \mathrm{mbar}$ and the pre-ionized density is $\sim 4 \times 10^{12} \mathrm{~cm}^{-3}$. At $1.5 \mathrm{~T}$ operating toroidal magnetic field, the $\mathrm{ECH}$ power is launched in fundamental O-mode. The ECH power at fundamental harmonic is varied from $100 \mathrm{~kW}$ to $250 \mathrm{~kW}$ and successful breakdown is achieved in all ECRH shots. In fundamental harmonic there is no delay in breakdown while at second harmonic $\sim 30 \mathrm{~ms}$ delay is observed, which has been observed in other tokamaks also [1-3]. The detailed discription of $42 \mathrm{GHz}$ ECRH system and SST experiments is mentioned in relevent sections.

\section{42GHz ECRH system on SST1}

The $42 \mathrm{GHz}$ ECRH system consists of high power Gyrotron, corrugated waveguide based transmission line and a mirror based launcher. The subsystem of ECRH system are mentioned as follows:

\subsection{Gyrotron}

The Gyrotron is procured from M/s. Gycom Russia, which delivers $500 \mathrm{~kW}$ power at
$42 \mathrm{GHz}$ frequency. The main operating parameters of Gyrotrons are beam voltage: $-50 \mathrm{kV}$, beam current: $20 \mathrm{~A}$, anode voltage: $+20 \mathrm{kV}$, cryomagnet current: $28.2 \mathrm{~A}$ and filament power $\sim 630 \mathrm{~W}$.

The Gyrotron system is equipped with two types of safety interlocks: fast interlock and slow interlock. The fast interlocks are arc, $\mathrm{dI}_{\text {beam }} / \mathrm{dt}$, beam over current, ion pump, while slow interlocks are cooling, filament and cryomagnet. The fast interlocks are hardwired, which removes the high voltage from gyrotron within $10 \mu \mathrm{s}$ and slow interlocks operate within $100 \mathrm{~ms}$. A two series Ignitron based crowbar system is used for the safe and reliable operation of Gyrotron.

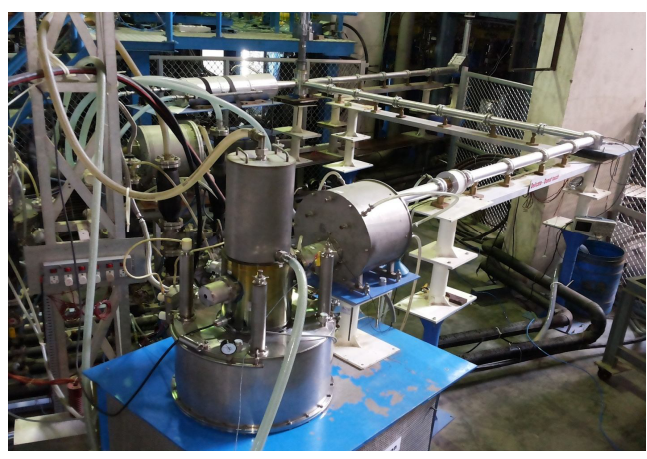

Figure 2 (Gyrotron system connected with Dummy Load)

The Gyrotron connected with dummy load is shown in figure 2. Initially the Gyrotron is operated at low power to monitor the normal operation of Gyrotron. Once the Gyrotron is conditioned with transmission line, the power and pulsed duration is increased to achieve the maximum parameters $(500 \mathrm{~kW}$ for $500 \mathrm{~ms}$ duration). The typical parameters for $500 \mathrm{~kW}$ power are: beam voltage: $\sim-50 \mathrm{kV}$, beam current $\sim 19 \mathrm{~A}$, anode voltage: $+20 \mathrm{kV}$, cryomagnet current: $28.1 \mathrm{~A}$ and filament power $\sim 630 \mathrm{~W}$. The typical ECRH pulse (Gyrotron operation on dummy load) at full parameters is shown in figure 3 . 


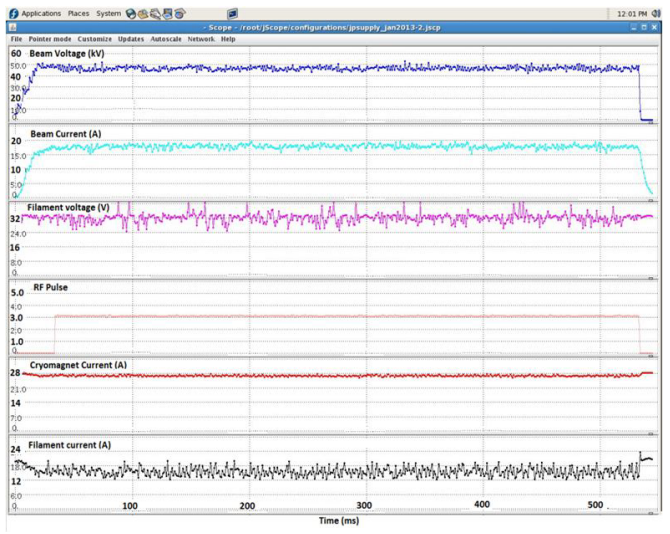

Figure 3 (500kW-500ms shot)

\subsection{Transmission line}

The transmission line consists of a matching optic unit (MOU), two DC breaks, mitre-bend with bi-directional coupler, polarizer, circular corrugated waveguide (inner diameter $63.5 \mathrm{~mm}$ ), bellows and two waveguide switches.

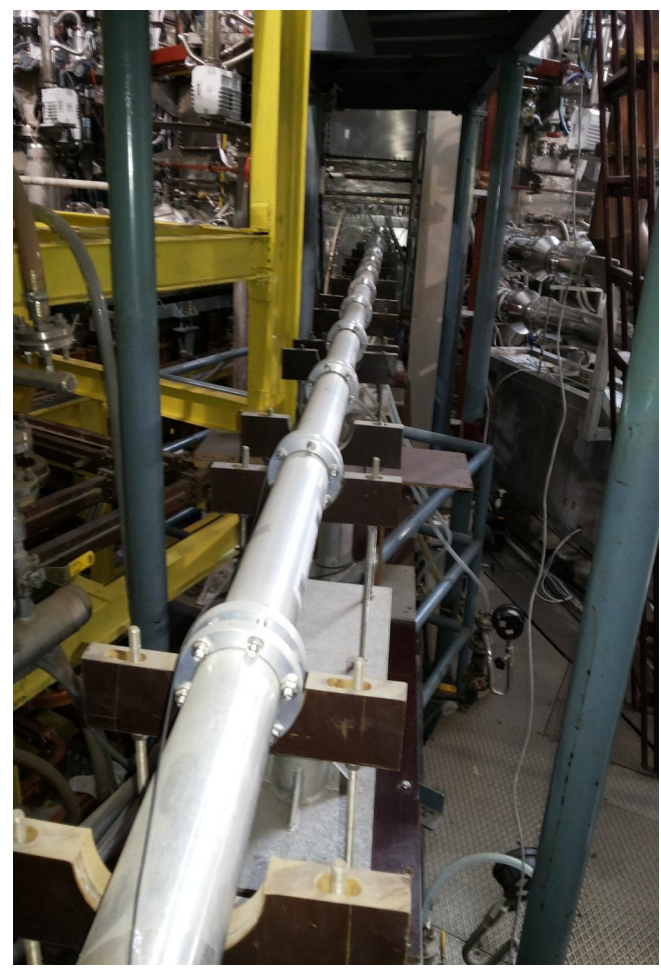

Figure 4 ECRH Transmission line connected to SST-1 tokamak
The first switch connected in the line facilitates to operate the gyrotron on dummy load or to launch the power in the tokamak, while the second switch gives an option to launch power either in tokamak SST-1 or in tokamak Aditya $[10,13]$. The total length of line for ECRH system on SST-1 is $\sim 20$ meters and total transmission loss of line is less than $1.1 \mathrm{~dB}$. The transmission line connected to tokamak is shown in Figure 4.

\subsection{Launcher}

There are two ECRH systems $42 \mathrm{GHz}-500 \mathrm{~kW}$ [10] and $82.6 \mathrm{GHz}-200 \mathrm{~kW}[11,12]$ used used in SST-1 to carry out ECRH experiments at $0.75 \mathrm{~T}, 1.5 \mathrm{~T}$ and $3.0 \mathrm{~T}$ magnetic fields. A composite launcher with four mirrors has been designned and fabricated to connect both the systems. The schematic of launcher is shown in figure 4. The distance between plasma centre and plane mirror is $900 \mathrm{~mm}$. The mirror size for $42 \mathrm{GHz}$ ECRH systems are $170 \mathrm{~mm} x$ $240 \mathrm{~mm}$, the focal length of mirror for $42 \mathrm{GHz}$ system is $353 \mathrm{~mm}$. The mirror's size for $82.6 \mathrm{GHz}$ launcher is $140 \mathrm{~mm} \times 200 \mathrm{~mm}$ and focal length for mirror is $481 \mathrm{~mm}$. The beam size at plasma centre for $42 \mathrm{GHz}$ launcher is $35 \mathrm{~mm}$ (1/e beam radius) and for $82.6 \mathrm{GHz}$ it is $20 \mathrm{~mm}$. The material of mirror is stainless steel (SS304L). The mirrors are fixed so beam steering is not feasible with this launcher.

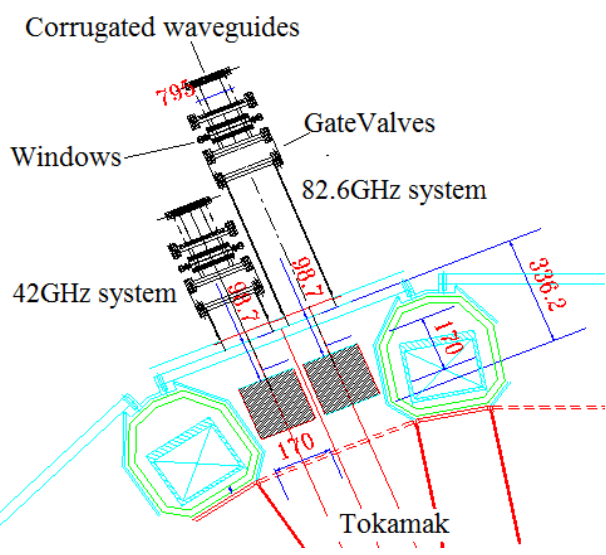

Figure 5 Schematic of ECRH launcher in SST-1 


\section{ECRH assisted breakdown in SST1}

Before starting the experiments on SST-1, entire ECRH system (Gyrotron with transmission line and tokamak window) conditioned and power launched directly in tokamak vacuum. The communication between ECRH control and SST control stablished, ECR pulsed synchronized with SST tokamak control. The plasma breakdown experiment on SST-1 tokamak has been carried out as follows:

\subsection{Second Harmonic ECRH assisted breakdown in SST-1}

The tokamak is oprerated at $0.75 \mathrm{~T}$ toroidal megnetic field, which corresponds to second harmonic at $42 \mathrm{GHz}$. The right-hand circular polarization is selected using polarizer, which is $\mathrm{X}$-mode $\left(\mathrm{E} \perp \mathrm{B}_{\mathrm{T}}\right)$. The Gyrorotron is operated for $\sim 300 \mathrm{~kW}$ power and considering $18 \%$ loss in the line, approximately $250 \mathrm{~kW}$ ECRH power is launched in tokamak. The pulse duration for ECRH is varied from $125 \mathrm{~ms}$ to $200 \mathrm{~ms}$ and the power is launched around $45 \mathrm{~ms}$ before the loop-voltage. The sucessful ECRH assisted breakdown is achieved in SST tokamak in all the shots at pressure $1 \times 10^{-5}$ mbar. The standard SST-1 plasma shots assisted with ECRH breakdown is shown in figure 6 .

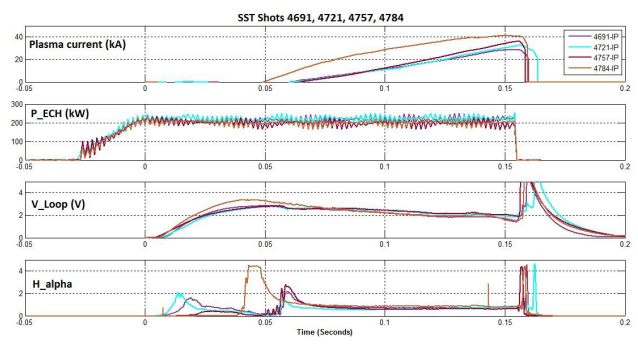

Figure 6 ECRH assisted plasma shots in SST-1

The loop voltage (trace 2) is $\sim 2.5 \mathrm{~V}$, the appearance of $\mathrm{H} \alpha$ (trace 5) confirms the $\mathrm{ECH}$ assisted breakdown in tokamak. There is a delay $\sim 50 \mathrm{~ms}$ in breakdown (loop voltage and $\mathrm{H} \alpha)$, which is expected at second harmonic
ECRH assisted breakdown. From the figure 6 it is clear that ECRH helps in plasma start-up and current ramp-up. The plasma current in typical plsma shots in SST-1 is achieved $53 \mathrm{kA}$.

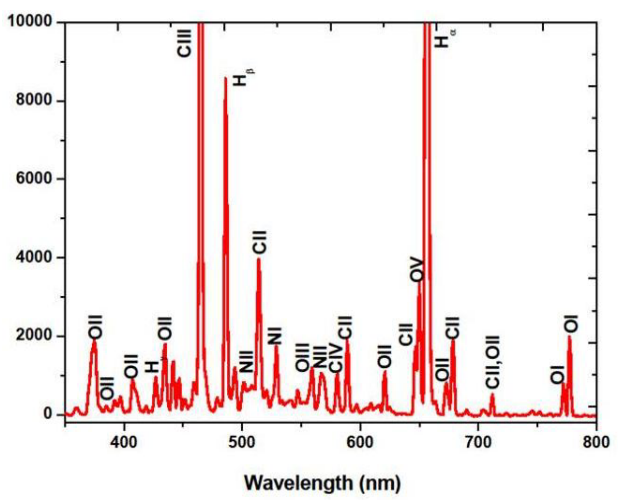

Figure 7 Spectroscopy data at flattop of Ip (SST-1 Shot)

The different plasma species are monitored using spectroscopy. Figure 7 shows the monitoring of hydrogen, carbon, oxygen and nitrogen lines at flat-top of plasma current. The presence of oxygen $(\mathrm{O}-\mathrm{V})$ gives the information on plasma temperature, it indicates that the plasma temperatue is more than $30 \mathrm{eV}$.

The position of plasma is also monitored with optical imaging. The camera used in the current set up is a $640 \times 480$ pixel CCD camera which is directly mounted on the machine. The viewing angle of this camera is around $70^{\circ}$ which covers nearly $60 \%$ of the vacuum vessel. The Optical Imaging Diagnostics on SST-1 provides information about plasma shape, vertical position, plasma movement in vertical direction. In the figure 8 , the plasma can be seen at a location (geometrical center of the machine) and diameter of the plasma to be around $50-55 \mathrm{~cm}$. A good plasma ring is observed (figure 8) with optical diagnostics which ensures the plasma is in machine center. 


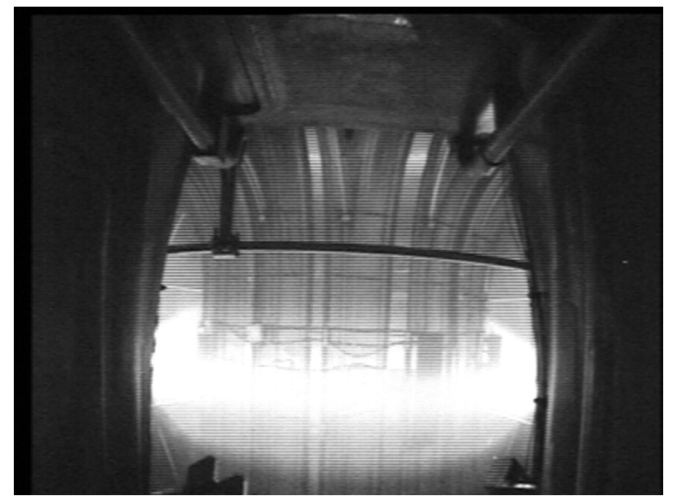

Figure 8 Plasma Ring in SST-1 (ECRH assisted plasma breakdown)

\subsection{Fundamental Harmonic ECRH assisted breakdown in SST-1}

The breakdown experiments at fundamental harmonic is also carried out in SST-1. The tokamak is oprerated at $1.5 \mathrm{~T}$ toroidal megnetic field and ECRH power is launched in Omode. In case of fundamental harmonic, the ECRH power is reduced to $100-200 \mathrm{~kW}$. The pulse duration is also reduced from $75 \mathrm{~ms}$ to $125 \mathrm{~ms}$. Since the maximum internal loop voltage in SST-1 appears around $20 \mathrm{~ms}$, so ECRH pulse is also synchronized from $-20 \mathrm{~ms}$ to $0 \mathrm{~ms}$ with respect to loop voltage. The sucessful breakdown is also achieved at fundamental harmonic in all the shots of SST1 with pressure range varied from $8 \times 10^{-8} \mathrm{mbar}$ to $3 \times 10^{-5} \mathrm{mbar}$. Figure shows that in case of fundamental harmonic there is instant breakdown without any significant delay, which is also expected at fundamental harmonic. The SST plasma shot assisted with ECRH breakdown at fundamental harmonic is shown in figure 9.

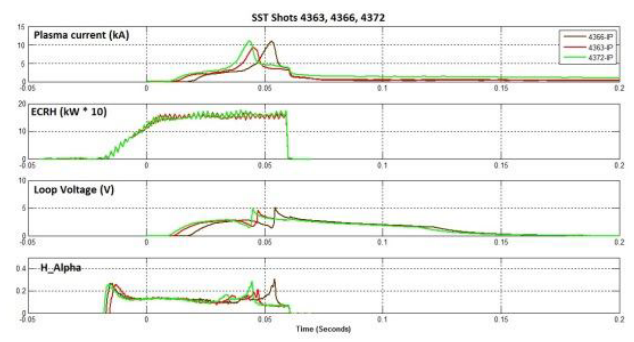

Figure 9 SST plasma shot at fundamental harmonic

\section{Discussion:}

The $42 \mathrm{GHz}-500 \mathrm{~kW}$ ECRH system has been successfully commissioned on tokamak SST1. The $42 \mathrm{GHz}$ system has been used to carry out plasma breakdown in SST-1 tokamak at fundamental and second harmonic. The systematic experimensts are carried out at second harmomic ECRH assisted breakdown in SST-1. In all these exeriments, successful breakdown is achieved at very low loop voltage $(\sim 2.8 \mathrm{~V})$. It is also observed that ECRH is contributing in plasma current rampup phase and various shots has been observed with plasma current $\sim 53 \mathrm{kA}$. There is delay in brekdown at second harmonic which is similar to breakdown in other machines.

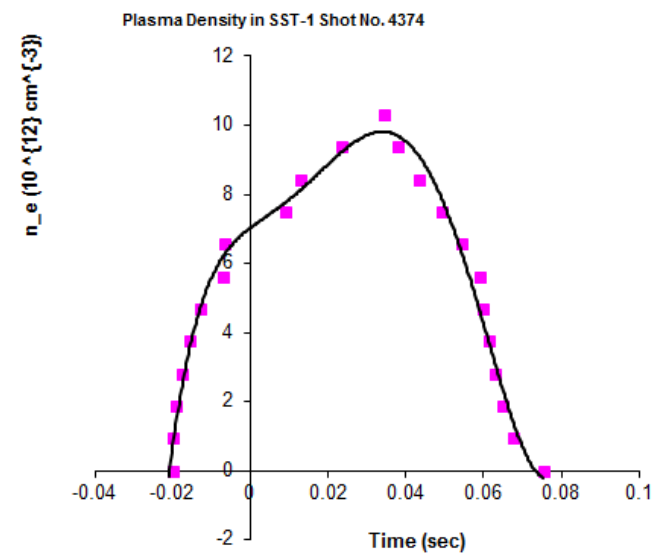

Figure 10a Density evolution in SST-1 tokamak with fundamental harmonic (1.5T) ECRF

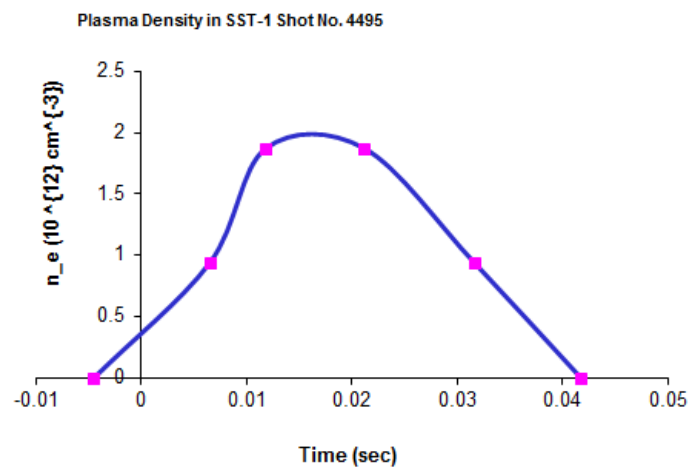

Figure 10b Density evolution in SST-1 tokamak with second harmonic (0.75T) ECRF

The breakdown at fundametal harmonic is also carried out and appearance of $\mathrm{H}_{-}$alpha with ECRH pulse confirms the instant 
breakdown at fundamental harmonic. The current ramp is also fast in case of breakdown at fundamental harmonic. The density is measured in case of fundamental and second harmonic breakdown (Figure $8 \mathrm{a}$ and $8 \mathrm{~b}$ ). The density is more in case of breakdown at fundamental harmonic. Although small dischares (plasma current $\sim 13 \mathrm{kA}$ ) are achieved in case of breakdown at fundametal harmonic but it is complete breakdown with burn-through of plasma with ECRH assistance. The systematic experiments at fundamenatl harmonic are scheduled in next campaign of SST plasma exeriments, in which plasma control will be done by various parameters like vertical field, pressure, ECR layer etc.

\section{Acknowledgement}

The authors would like to thank SST-1 team for extended cooperation during entire campaign. The author would like to thank all the members of diagnostics for their support to give required information on plasma diagnostics.

\section{References}

1. B. LLOYD et al., 'low voltage ohmic and Electron Cyclotron heating assisted startup in DIII-D' Nuclear Fusion, Vol.31, No:11, 20312053, 1991.

2. F. LEUTERER et al. "Recent ECRH results in ASDEX Upgrade" Nuclear Fusion, Vol. 43 (2003), 1329-1342

3. M. ROMÉ, V. ERCKMANN, U. GASPARINO, and N. KARULIN, Electron cyclotron resonance heating and current drive in the W7-X stellarator, Plasma Phys. Control. Fusion 40 (1998) 511-530.

4. R. WILHELM et al., Plasma Physics and Controlled Fusion, 26 (1984) pp 259-261

5. D. R. WHALEY, T.P. GOODMAN, A. POCHELON, R. BEHN, A. CARDINALI, B.P. DUVAL, B. JOYE AND M.Q. TRAN, 'X- and O-mode electron cyclotron heating breakdown and startup in TCA', Nuclear Fusion, Vol.32, 757-771, 1992.

6. O. SAUTER, M.A. HENDERSON, T. GOODMAN et al, "Steady-state fully non inductive current driven by electron cyclotron waves in magnetically confined plasma" Physical Review Lett.84 (15) (2000) 3322
7. V. ERCKMANN et al, "Electron cyclotron resonance heating and current drive in toroidal fusion plasmas" Plasma Phys. Control Fusion36 (1994) 1869

8. G. GANTENBEIN et al, "Complete suppression of neoclassical tearing modes with current drive at the electron cyclotron resonance frequency in the ASDEX upgrade tokamak" Phys. Rev. Lett.85, (2000) 1242-1245

9. R.J. LAHAYE et al, "Suppression of neoclassical tearing modes in the presence of sawteeth instabilities by radially localized offaxis ECCD in the DIII-D tokamak" Proc. $28^{\text {th }}$ EPS conference on Controlled Fusion and Plasma Physics, vol. 25A, PP 1357- 1360, 2001

10. B. K. SHUKLA et.al. "42-GHz 0.5-MW ECRH System for Tokamaks SST-1 and Aditya", IEEE Trans. on Plasma Science Volume: 40 , Issue: 4 Page(s): 1234 - 1238

11. Y. C. Saxena Nuclear Fusion vol. 40, No. 6, (2000) 1069-1082

12. D. Bora et.al. TCM on SSO of Magnetic Fusion devices - IAEA conference, Germany, 2-3 May, 2002

13. S. B. BHATT, Indian Journal of Pure and Applied Physics, vol.27 (1989) P710

14. B. K. SHUKLA et.al. "Characterization of Quasi-Optical Launcher for ECRH in SST-1" Fusion Science and Technology, vol. 45, 4 (2004) 549-557 